\title{
Task force on chronic interstitial lung disease in immunocompetent children
}

\author{
A. Clement*, and committee members \\ Committee members: J. Allen, B. Corrin, R. Dinwiddie, H. Ducou le Pointe, E. Eber, G. Laurent, R. Marshall, F. Midulla, A.G. Nicholson, \\ P. Pohunek, F. Ratjen, M. Spiteri, J. de Blic. All members of the Task Force contributed equally to the work.
}

Task force on chronic interstitial lung disease in immunocompetent children A. Clement, and committee members. C) ERS Journals Ltd 2004.

ABSTRACT: Chronic interstitial lung diseases in children represent a heterogeneous group of disorders of both known and unknown causes that share common histological features. Despite many efforts these diseases continue to present clinical management dilemmas, principally because of their rare frequency that limits considerably the possibilities of collecting enough cases for clinical and research studies.

Through a Task Force conducted by the European Respiratory Society, which comprised respiratory physicians and basic scientists from across Europe, 185 cases of interstitial lung diseases in immunocompetent children were collected and reviewed. The present report provides important clinically-relevant information on the current approach to diagnosis and management of chronic interstitial lung diseases in children. In addition, recommendations for the management of paediatric interstitial lung diseases, as well as new insights into interstitial lung diseases pathophysiology during childhood are discussed.

Eur Respir J 2004; 24: 686-697.
Correspondence: A. Clement, Dept de Pneumologie Pediatrique - INSERM E213, Hopital d'enfants Armand Trousseau, 26 Ave du Dr Arnold Netter, 75571 Paris cedex 12, France.

Fax: 33144736718

E-mail: annick.clement@trs.ap-hop-paris.fr

Keywords: Children, infant, interstitial lung disease, lung fibrosis

Received: August 52003

Accepted after revision: June 72004
Chronic interstitial lung diseases (ILD) represent a heterogenous group of disorders of both known and unknown causes that share common histological features. To date, these disorders have been poorly investigated in children; indeed most of the strategies used by paediatricians for diagnosis and treatment are derived from information provided by studies in adult patients [1, 2]. However, there is increasing evidence that expression and outcome of chronic ILD in children differs from adult ILD. The present study was conducted as part of a European Respiratory Society (ERS) Task Force on chronic ILD in immunocompetent children. The objectives of the Task Force were: 1) to provide information on the current approach to diagnosis and management of chronic ILD in children; 2) to provide recommendations to clinicians for the diagnosis and management of chronic ILD in children; 3) to provide an update on the current understanding of the pathophysiology of the disease(s) and on ongoing research directions; and 4) to develop clinical and scientific collaborations across the paediatric discipline and also with adult researchers to enable progress in the identification of mechanisms underlying disease initiation and progression in infants and older children.

\section{Review of the current approach to diagnosis and management of chronic ILD in children}

\section{Study population}

The Task Force included clinical respiratory physicians involved in paediatric and adult ILD, as well as basic scientists with expertise in cellular and molecular biology, and in genetics. Each member was assigned to contact the

For editorial comments see page 521. various paediatric pulmonary departments in European countries, and to collect cases of chronic ILD through a questionnaire established by the group. This cohort is, thus, fairly representative of practice across Europe. Data were then pooled and discussed through a series of meetings. Chronic ILD in immunocompetent children was defined as the presence of respiratory symptoms and/or diffuse infiltrates on chest radiographs, abnormal pulmonary function tests with evidence of restrictive ventilatory defect and/or impaired gas exchange, and persistence of any of these findings for $>3$ months [1-5]. The medical records of children actively managed for chronic ILD in European paediatric centres from 1997-2002 were reviewed. The records of 185 patients with a diagnosis of chronic ILD were identified based on the criteria defined above, and analysed. The exclusion criteria were lung diseases associated with immunodeficiency and/or malignancy. All the information regarding patient background including familial history, patient presentation, diagnostic evaluation, final diagnosis, treatment and outcome were recorded through the questionnaire. All the results were then collected into a database. In order to provide information on chronic ILD in young children, a subgroup of 58 patients aged $<2$ yrs was individualised. Results are presented as descriptive data and as mean \pm SD.

\section{Patient presentation and diagnostic evaluation}

Paediatric ILD occurred more frequently in the younger patients (fig. 1). A summary of the patients is listed in table 1 . The prevalence for development of chronic ILD was higher in young males than in young females. This is in agreement with other reports $[2,6]$. Medical record review of the family members indicated that nearly $10 \%$ of case siblings were affected by similar diseases. 


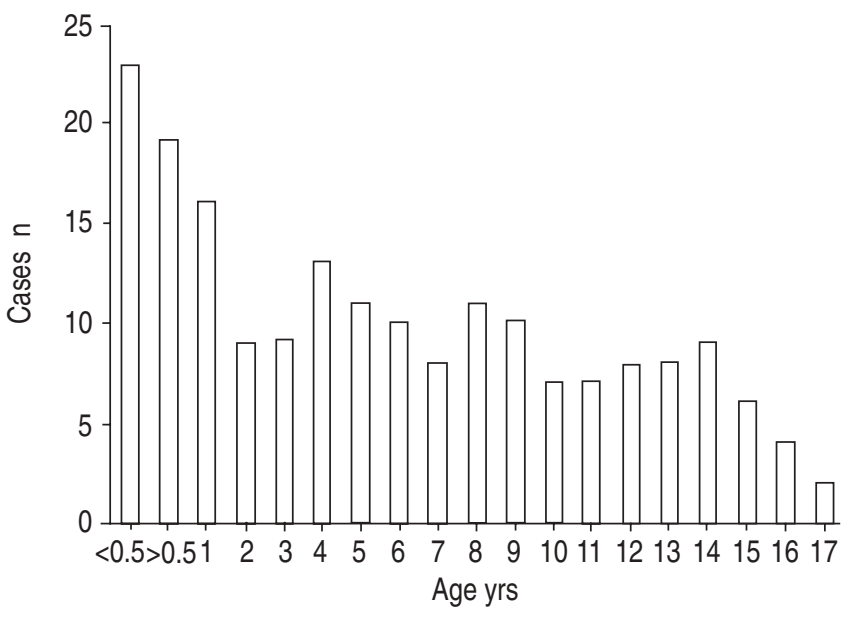

Fig. 1.-Age distribution (in yrs) of the patients with interstitial lung diseases included in the European Respiratory Society Task Force study.

Table 1.-Clinical presentation of the patients with interstitial lung disease

\begin{tabular}{|c|c|c|c|c|}
\hline & \multicolumn{2}{|c|}{ All patients } & \multicolumn{2}{|c|}{ Patients aged $<2$ yrs } \\
\hline & $\mathrm{n}$ & $\%$ & $\mathrm{n}$ & $\%$ \\
\hline Patients $\mathrm{n}$ & 185 & & 58 & \\
\hline Sex male/female & $108 / 77$ & $58 / 42$ & $35 / 23$ & $60 / 40$ \\
\hline \multicolumn{5}{|l|}{ Ethnic origin } \\
\hline Caucasian & 162 & 87.6 & 52 & 89.7 \\
\hline Black & 18 & 9.7 & 4 & 6.9 \\
\hline Other & 5 & 2.7 & 2 & 3.4 \\
\hline Parental consanguinity & 13 & 7 & 5 & 9 \\
\hline Affected siblings & 18 & 10 & 8 & 7 \\
\hline \multicolumn{5}{|l|}{ Symptoms } \\
\hline Cough & 145 & 78 & 42 & 73 \\
\hline Tachypnoea/dyspnoea & 140 & 76 & 49 & 84 \\
\hline Failure to thrive & 68 & 37 & 36 & 62 \\
\hline Fever & 37 & 20 & 17 & 29 \\
\hline \multicolumn{5}{|l|}{ Physical findings } \\
\hline Cyanosis & 51 & 28 & 31 & 54 \\
\hline Clubbing & 24 & 13 & 5 & 9 \\
\hline Crackles & 81 & 44 & 33 & 57 \\
\hline
\end{tabular}

The majority of patients had symptoms for $<1 \mathrm{yr}$ at the time of initial evaluation. The mean duration of symptoms before diagnosis was $6.6 \pm 0.5$ months. Most children presented with cough and tachypnoea (table 1). Failure to thrive was documented in almost two thirds of the patients diagnosed before aged 2 yrs.

Chest radiographs were performed in all patients, but highresolution computed tomography (HRCT) scanning data were available in only 131 of 185 cases (and in 37 of 58 patients aged $<2 \mathrm{yrs}$ ). Abnormalities at the time of initial evaluation were predominantly interstitial infiltrates (table 2). Analysis of the pulmonary function data showed large variations in the methods used by the various paediatric centres. The results summary of gas exchange analysis, lung volumes, and diffusion capacity for carbon monoxide $(D \mathrm{co})$ tests that could be included in the present review are presented in table 2. Hypoxaemia was documented by blood gas analysis in two thirds of patients.

Bronchoalveolar lavage (BAL) was performed in 119 cases, and data on BAL cell populations were available in 98 cases (and for 21 patients aged $<2 \mathrm{yrs}$ ). Results are presented in table 2; generally, there is evidence of BAL lymphocytosis
Table 2. - Diagnostic evaluation of the patients with interstitial lung disease

\begin{tabular}{lcc}
\hline & All patients & Patients aged $<2$ yrs \\
\hline Patients n & 185 & 58 \\
Chest imaging & & \\
$\quad$ Infiltrates & 128 & 36 \\
Ground glass pattern & 34 & 11 \\
Honeycomb pattern & 4 & 1 \\
Pulmonary function tests & 122 & \\
$\quad \mathrm{a}_{\mathrm{O}} \mathrm{O}_{2}$ & 73 & 36 \\
$\quad \mathrm{Sa}, \mathrm{O}_{2}<95 \%$ & 112 & \\
$P \mathrm{a}, \mathrm{O}_{2}$ & 67 & \\
$\quad \mathrm{Hypoxaemia}$ & 108 & $\mathrm{ND}$ \\
Lung volume & 78 & $\mathrm{ND}$ \\
$\quad$ Restriction & 75 & \\
Dco & 43 & 98 \\
$\quad$ Reduction & & $65.2 \pm 17.1$ \\
BAL & 98 & $13.8 \pm 11.6$ \\
Cell population data & $53.8 \pm 20.9$ & $1.3 \pm 20.5$ \\
Macrophage \% & $32.2 \pm 22.6$ & 1.6 \\
Lymphocyte \% & $11.3 \pm 16.5$ & \\
Neutrophil \% & $1.2 \pm 1.6$ & \\
Eosinophil \% &
\end{tabular}

Data are presented as $\mathrm{n}$ or mean $\pm \mathrm{SD} . \mathrm{Sa}, \mathrm{O}_{2}$ : arterial oxygen saturation; $P a, \mathrm{O}_{2}$ : arterial oxygen tension; $D$ co: diffusion capacity for carbon monoxide; BAL: Bronchoalveolar lavage; ND: not determined.

and neutrophilia; however, in the younger aged children BAL cell populations were predominantly neutrophils.

The main laboratory tests performed were microbiology tests, with data available in 111 cases. Positive results were found in 10 samples, with the detection of adenovirus (one case), Epstein Barr virus (EBV; four cases), Influenza virus (one case), parvovirus (one case), cytomegalovirus (two cases) and Mycoplasma pneumoniae (one case). The other laboratory tests were performed according to the patient history and clinical presentation. Search for circulating auto-antibodies was done in 99 samples with positive results in 12 cases. Elevated levels of angiotensin converting enzyme (ACE) were performed in 10 cases, and screening tests for hypersensitivity pneumonitis were considered positive for 20 children.

Lung biopsy data were available in 107 cases. Analysis of the diagnostic procedures performed indicated that open lung biopsies were predominantly performed $(62 \%)$, followed by transbronchial biopsies $(26 \%)$, video assisted thoracoscopy biopsies (VATB) (7\%), and transthoracic percutaneous biopsies $(5 \%)$

\section{Diagnosis}

A diagnosis was made in 177 of 185 patients, and in 56 of 58 cases in the subgroup of children aged $<2$ yrs. The list is given in table 3, including the number of lung biopsies performed. Some can be considered as specific diagnoses, in accordance with the standard classification of chronic ILD $[6,7]$. They include pulmonary haemosiderosis, pulmonary alveolar proteinosis, hypersensitivity pneumonitis, Langerhans cell histiocytosis, sarcoidosis, pulmonary lymphangioleiomyomatosis, lymphocyte infiltrative disorders, and auto-immune related ILD. The other diagnoses reported by the various centres can be collectively labelled as "idiopathic interstitial pneumonia". They include desquamative interstitial pneumonitis (DIP), usual interstitial pneumonitis (UIP), and lymphoid interstitial pneumonitis (LIP). In 67 cases, the reported diagnoses were idiopathic pulmonary fibrosis and interstitial pneumonitis, respectively. 
Table 3.-Diagnoses in patients included in the European Respiratory Society Task Force study

\begin{tabular}{cc} 
Patients & $\begin{array}{c}\text { Lung } \\
\text { biopsy }\end{array}$ \\
\hline All $\quad \begin{array}{c}\text { Aged } \\
<2 \text { yrs }\end{array}$ &
\end{tabular}

\begin{tabular}{lccc}
\hline Pulmonary haemosiderosis & 14 & 5 & 6 \\
Pulmonary alveolar proteinosis & 14 & 7 & 7 \\
Hypersensitivity pneumonitis & 24 & 0 & 8 \\
Langerhans cell histiocytosis & 3 & 3 & \\
Sarcoidosis & 29 & 1 & 11 \\
Pulmonary lymphangioleiomyomatosis & 1 & & 1 \\
Lymphocyte infiltrative disorder & 1 & & \\
$\begin{array}{l}\text { Auto-immune related interstitial lung } \\
\quad \text { disease }\end{array}$ & 3 & & \\
Desquamative interstitial pneumonitis & 13 & 11 & 13 \\
Usual interstitial pneumonitis & 7 & 2 & 7 \\
Lymphoid interstitial pneumonitis & 1 & & \\
Idiopathic pulmonary fibrosis & 46 & 12 & 32 \\
Interstitial pneumonitis & 21 & 15 & 17 \\
\hline
\end{tabular}

Data presented as $n$.

\section{Treatment and outcome}

Oxygen therapy was used in all patients with documented hypoxaemia at the time of diagnosis. The need for long term supplemental $\mathrm{O}_{2}$ was indicated in 48 children, mainly in the subgroup of patients aged $<2$ yrs. Among the therapeutic regimes administered at the time of diagnosis, systemic corticosteroids were the preferred therapy, and appeared to be used in various dosages and over variable durations. As indicated in table 4 , the steroid treatment was administered orally and/or by $i . v$. The other drug administered in $18 \%$ of the cases alone or in association with steroids was hydroxychloroquine. Review of patient records revealed that the preferred choice between steroids or hydroxychloroquine was highly dependent on the expertise of the various centres, and did not seem to be influenced by the type of chronic ILD. In rare situations, other treatments including azathioprine, cyclophosphamide, methotrexate, and granulocyte macrophagecolony stimulating factor GM-CSF were used. In addition, patients with pulmonary alveolar proteinosis were managed with repeated therapeutic BAL.

The mean duration of follow-up in the total population was $2.2 \pm 3.1 \mathrm{yrs}$, with a mean duration of treatment of $1.2 \pm 0.9$ yrs. These durations were longer in the subgroup of infants (respectively $3.4 \pm 3.5 \mathrm{yrs}$, with a mean duration of treatment of $2.6 \pm 2.8 \mathrm{yrs}$ ). From the information reported

Table 4. - Treatment of patients with interstitial lung diseases

\begin{tabular}{lcc}
\hline & $\begin{array}{c}\text { All } \\
\text { patients }\end{array}$ & $\begin{array}{c}\text { Patients } \\
\text { aged }<2 \text { yrs }\end{array}$ \\
\hline Patients n & 172 & 56 \\
Long-term oxygen & 48 & 32 \\
Steroids & 138 & 36 \\
$\quad$ Oral & 40 & 14 \\
$\quad$ i.v. & 34 & 12 \\
$\quad$ Oral and $i . v$. & 27 & 24 \\
Hydroxychloroquine & 5 & 4 \\
Hydroxychloroquine and steroids & 22 & 2 \\
Other treatments & & \\
\hline
\end{tabular}

Data presented as n. Other treatments include azathioprine, methotrexate, cyclophosohamide and granulocyte macrophage-colony stimulating factor. in the records, evaluation of patient outcome could be documented in 174 cases and indicated improvement in 129 cases ( 34 in the subgroup of infants), stabilisation in 30 cases (22 in the subgroup of infants), deterioration in four cases (one in the subgroup of infants), and death in 11 cases (one in the subgroup of infants). Due to the heterogeneity of patient management, it appeared difficult in this retrospective analysis to relate the outcome in terms of diagnosis and preferred therapeutic strategy. For the patients who died, the reported diagnoses were pulmonary haemosiderosis (one case), pulmonary proteinosis (two cases), Langerhans cell histiocytosis (one case), UIP (one case), interstitial pneumonitis (three cases), and idiopathic fibrosis (three cases).

\section{Comments}

This is the first study to collect the largest population of chronic ILD in children from across Europe. It was made possible by a strong and efficient collaboration between a number of pulmonary paediatric European centres. Despite efforts to include as many cases as possible, the recruitment cannot be considered as exhaustive and consequently did not provide information on the actual incidence and prevalence of paediatric ILD across Europe [8]. Nevertheless, the reported 185 cases integrated into the database allowed evaluation and determination of the prevailing approach to management of paediatric ILD, and exploration of whether standards of care in this disease could be improved in the future.

Analysis of the population included in the present study revealed that the management of these patients was not standardised and appeared to be extremely ad hoc, varying from centre to centre, depending on resources and expertise. Also, as indicated above, analysis of the pulmonary function data showed significant variations in the methodology used across the groups. It is interesting to note that noninvasive tests were considered as sufficient for the diagnosis of chronic ILD in 78 children. In patients who underwent lung biopsy, the technique of choice was open lung biopsy (OLB), mainly in the younger age group [9]. Based on the results of patient history and presentation, noninvasive tests, and in some situations of lung biopsy, a diagnosis was made in 177 cases. From the information provided by the centres, it was possible to individualise a number of well-defined diagnoses, such as DIP, UIP, and LIP. However, in 67 cases, the reported diagnosis was incompatible with the standard descriptive classification. Thus, in this group of cases, the Task Force agreed to retain the diagnosis of idiopathic pulmonary fibrosis or interstitial pneumonitis, as originally proposed by the physicians in charge of the said patients.

The main therapeutic strategy was corticosteroids. As indicated above, the choice between steroids and hydroxychloroquine was highly centre-dependent $[5,6,10,11]$. The diversity of the diagnoses and the heterogeneity of the recruited population did not allow information to be drawn on which therapeutic strategy would be more beneficial for a given pathological situation. The present review highlights a number of differences in the management of children with chronic ILD among the various paediatric centres. Many questions remain unanswered; specifically, they relate to the types of investigations required to make a firm diagnosis, the requisite techniques to analyse lung biopsy specimens and to help clarify a working ILD classification in children, the tools essential in assessment of disease severity and progression, and guidelines to optimise and standardise therapy. Interestingly, the present data highlighted familial cases as well as cases associated with parental consanguinity. Clearly, new approaches need to be exploited in terms of the role of genetic 
predisposition and the identification of specific aetiological factors based on the current knowledge of pathophysiology in adult cases.

\section{Recommendations for diagnosis and treatment of chronic ILD in children}

\section{Clinical evaluation}

The presenting clinical manifestations are often subtle and nonspecific $[4,5,12]$. The onset of symptoms is, in most cases, insidious and many children may have had symptoms for years before the diagnosis of ILD is confirmed. The clinical manifestations vary from asymptomatic presentation with radiological features suggestive of ILD to the more characteristic presence of respiratory symptoms and signs of cough, dyspnoea, tachypnoea and exercise intolerance. These varying presentations are reflected in the report published by FAN et al. [13] who systematically evaluated the clinical symptoms and physical findings of 99 consecutive children with ILD observed at the University of Colorado from 1980-1994 [13]. Common symptoms at presentation included cough, dyspnoea, tachypnoea and chest wall retraction, exercise limitation and frequent respiratory infections. Although a history of wheezing could be elicited in almost $50 \%$ of the patients, wheezing could be documented by physical examination in only $20 \%$ of the cases. Any child with a normal birth history, presenting with the signs and symptoms suggestive of ILD lasting for $>3$ months should be evaluated for ILD. A systematic approach to the diagnosis of ILD in children is essential, and should start with an accurate clinical history and physical examination, followed by physiological and laboratory investigations to rule out nonrespiratory diseases associated with lung involvement [2].

It is recommended that clinical history-taking starts by obtaining general information on the relatives or siblings with similar lung conditions. Details should also be obtained on precipitating factors, such as feeding history, any acute or severe respiratory infections, environmental exposure to organic and inorganic dust, and use of drugs with pulmonary toxicity. The history should also note the presence and onset of respiratory symptoms, such as cough, tachypnoea, dyspnoea, effort intolerance, tiring during feeding, wheezing, respiratory infection, haemoptysis and failure to thrive [2]. Cough presents in almost $75 \%$ of the patients, is normally nonproductive and does not disturb sleep. It is described as an itching or tingling sensation in the throat. Tachypnoea is present in $80 \%$ of patients and is usually the earliest and most common respiratory symptom. It is associated with subcostal or intercostal retractions.

The frequent clinical findings are inspiratory crackles, tachypnoea and retraction. In a child with a normal birth history, these are strongly suggestive of ILD. Rarer findings associated with an advanced stage of the disease include finger clubbing and cyanosis during exercise or at rest. During the physical examination it is essential to look for the presence of associated nonrespiratory symptoms, such as joint disease, cutaneous rashes, recurrent fever typical of collagen-vascular disorders and failure to thrive.

\section{Laboratory tests}

Laboratory tests are seldom diagnostic in ILD, but may be helpful to exclude other systemic disorders, such as immunodeficiencies or collagen vascular diseases that can be associated with interstitial lung involvement. Laboratory tests are also used to exclude more common respiratory diseases in childhood that do not typically present with diffuse pulmonary disease, such as cystic fibrosis, tuberculosis or gastrooesophageal reflux with chronic lipid aspiration. Rather than performing an expensive diverse battery of tests in every patient with undefined ILD, the spectrum of investigations should be guided by the history and clinical presentation in each individual child.

Pulmonary infections, particularly those causing atypical pneumonia, are considered in the differential diagnosis of virtually every case with ILD. Serological tests are insufficient to prove a pulmonary infection and can only be regarded as suggestive. Any infection should be proven by detection of the pathogen in either BAL fluid or lung tissue (see below). Many infectious organisms have been claimed to be associated with ILD in adults, although a causal relationship has not been proven in most instances [14-17]. There are few data available for children and, given the high frequency of viral respiratory infections in this age group per se, it is extremely difficult to ascertain a causal contribution in this age group. An "alveolitis", although unclassified, has been found in two infants with EBV infection; again there is little proof as to the actual cause of their lung disease [18].

Precipitating immunoglobulin $\mathrm{G}$ antibodies against airborne allergens can be used as indirect evidence for hypersensitivity pneumonitis. As an example, positive antibodies are found in up to $20 \%$ of subjects exposed to pigeon antigens not developing hypersensitivity pneumonitis [19]. Panels of screening tests for hypersensitivity pneumonitis are of questionable value and a thorough history should always precede specific tests. ILD associated with pulmonary haemorrhage can be due to systemic diseases, such as Goodpasture's syndrome, lupus erythematosous or Wegener's granulomatosis. Laboratory tests in these patients should, therefore, include antibodies against basement membrane, antinuclear antibodies against double strand DNA, and antineutrophilcytoplasmatic autoantibodies. Although false positive results do occur, these antibodies are quite specific for these three entities [20-24]. In paediatric patients with sarcoidosis mild elevation of ACE, as well as hypercalcaemia and hypercalciuria, can be observed $[25,26]$.

\section{Chest imaging}

Plain radiographs are usually performed in a child suspected of ILD at first presentation, but the information provided is often limited. In addition, there are reported cases of biopsy-proved ILD with normal chest radiographs. Lungs are difficult to image with magnetic resonance imaging due to low proton content, and this method has not yet demonstrated any utility to explore patients with ILD. Consequently, the key chest imaging tool for the diagnosis and management of a patient with ILD is HRCT, which can visualise the parenchymal structure to the level of the secondary pulmonary lobule. Recent paediatric literature confirms that HRCT increases the level of diagnostic confidence for infiltrative lung disease [27-32]. HRCT has now been proven to be useful for ILD diagnosis in children, and for patient management by helping to select the lung area to be biopsied. HRCT may also contribute to monitor disease activity and/or severity.

HRCT technique for ILD diagnosis has been extensively discussed. To optimise spatial resolution, there is a general agreement to use thin sections, the smallest field of view and a sharp resolution algorithm. For the thin section, a $1 \mathrm{~mm}$ collimation is recommended. Field of view should be chosen to encompass the patient. Some authors propose a targeting 
image reconstruction to a single lung to reduce pixel size. High spatial frequency algorithm (bone algorithm) is indicated in order to improve spatial resolution and increases image sharpness and the visibility of image noise. To reduce image noise, some authors suggest a $120-140 \mathrm{kVp}$ and 100-200 mAs technique in children. LUCAYA et al. [33] demonstrated that HRCT performed with 180 or $50 \mathrm{mAs}$ techniques produces images of similar quality. Based on the various technical reports now available, the ERS Task Force recommends the use of $120 \mathrm{kVp}$ and $50 \mathrm{mAs}$ for performing chest HRCT in paediatric patients. HRCT is generally performed with $10 \mathrm{~mm}$ intervals, and $20 \mathrm{~mm}$ intervals can be used for the follow-up. Expiratory slices are useful to document obstructive small airways diseases. Three additional expiratory slices (one in the upper, one in the middle and one in the lower lobes) could be undertaken in such cases.

In most radiological departments, HRCT is performed without sedation in children aged $>3$ yrs or $<6$ months. Our recommendation is to avoid general anesthesia and to use conscious sedation only if necessary, chloral hydrate being among the most commonly used agents for sedation of infants and children prior to computed tomography, at a dose of $50-75 \mathrm{mg} \cdot \mathrm{kg}^{-1}$. Should sedation be recommended, it needs to be done according to the Guidelines for monitoring and management of paediatric patients during and after sedation for diagnostic and therapeutic procedures, published by the American Academy of Paediatrics [34].

The description of the HRCT findings follows the glossary of terms published by the Nomenclature Committee of the Fleischner Society [35]. In rare cases, HRCT findings may permit the diagnosis of some infiltrative lung diseases, such as pulmonary alveolar microlithiasis [36]. In Langerhans cell histiocytosis, HRCT detects peribronchial or peribronchiolar granulomas, which appear as micronodules mainly found in the upper and middle lung zones. In this disease, lesions seem to progress from nodules to cavitary nodules, to thick-walled cysts and finally to thin-walled cysts [27]. In extrinsic allergic alveolitis, HRCT abnormalities depend on the stage of the disease [37]. At an early stage, HRCT findings are mainly patchy ground-glass opacities, small nodules with peribronchiolar or centrilobular distributio, and areas of decreased attenuation. In advanced forms of the disease, fibrotic lesions can be observed, which seem to spare the lungs bases. In sarcoidosis, HRCT shows granulomas distributed along the lymphatics in the bronchovascular sheath and in the interlobar septa and pleura [27]. Most nodules are $2-10 \mathrm{~mm}$ in diameter, have irregular margins and occur in a perilymphatic distribution, giving rise to a beaded appearance of the bronchovascular bundles and interlobular septa and fissural nodularity. Large parenchymal nodules represent coalesced granulomas. Ground-glass opacities seem to be due to the presence of numerous sarcoid granulomas below the resolution of HRCT.

In other forms of ILD, HRCT findings are less specific, with the most common HRCT feature being widespread ground-glass attenuation. SEELy et al. [27] reported that the areas of ground-glass attenuation involved mostly the subpleural regions. Intralobular lines, irregular interlobular septal thickening and honeycombing seem to be less common findings and, thus, less contributive to diagnosis. Large subpleural air cysts in the upper lobes adjacent to areas of ground-glass opacities seem to be unique to childhood ILD. These cysts are interpreted as paraseptal or irregular emphysema. COPLEY and PADLEY [29] reported six cases of nonspecific interstitial pneumonia in children [29]. In three, HRCT showed a predominantly upper-zone honeycomb pattern with parenchymal distortion superimposed on a background of widespread ground-glass opacification. As discussed in the adult ILD, the presence of ground-glass opacities without HRCT findings of fibrosis may be a marker of an active disease [29, 30, 38-40]. However, HRCT still needs evaluation as a follow-up tool in paediatric patients.

\section{$B A L$ studies}

A recent ERS Task Force on BAL in children provided recommendations about indications, processing, and "normal" values for paediatric BAL [41]. Usually, BAL is carried out in the most affected area (identified radiologically and/or endoscopically). In diffuse ILD, BAL is mostly performed in the right middle lobe, or, for infants, in the lower lobe. The instilled fluid is pre-warmed (to body temperature) sterile saline. It is recommended that the total volume of saline instilled is $3 \times 1 \mathrm{~mL} \cdot \mathrm{kg}^{-1}$ in $10-20 \mathrm{~mL}$ aliquots. The return fluid of BAL is used for microbiological and cytological analysis, and in some specific cases for other cellular and noncellular studies [42, 43].

In cases of infections, BAL can provide specimens for cytological examination, microbial cultures, and molecular analysis. However, results should always be interpreted with caution, mainly because of possible contaminations of the alveolar samples during the procedure.

In pathological situations other than infections, BAL can have several indications. BAL is diagnostic for pulmonary alveolar proteinosis, which is characterised by milky appearing fluid, abundant extracellular and intra-macrophage proteinaceous periodic acid-Schiff-positive material, and presence of foamy alveolar macrophages (AM), [41]. Other investigations that can be proposed are studies of various surfactant components, phospholipids and apoproteins [44]. BAL can also be diagnostic for pulmonary alveolar haemorrhage. This diagnosis is made easy when the return BAL fluid has a bloody or pink colour, but its gross appearance may be normal. Microscopic analysis may then be of value by documenting the presence of red blood cells in AM or haemosiderin laden AM [45]. The diagnosis of Langerhans cell histiocytosis can be performed with the use of the monoclonal antibodies revealing the presence of CD1a positive cells (in $>5 \%$ of BAL cells) [46]. Lipid disorders with lung involvement represent another indication of BAL. This includes congenital lipid-storage diseases (Gaucher's disease and Niemann-Pick disease) or chronic lipid pneumonia due to chronic aspiration [47, 48]. However, in cases of aspiration syndromes, the presence of lipid laden AM may be sensitive but not specific [49].

In other pathological situations, BAL can usefully serve to direct further investigations. Accumulation of BAL T-lymphocytes with prevalence of CD4+ cells is suggestive of sarcoidosis, whilst prevalence of CD8+ cells is suggestive of hypersensitivity pneumonitis [50]. Also, an increase in BAL eosinophils suggests pulmonary infiltrates associated with eosinophilia syndromes [51]. Finally, BAL may help identifying lung involvement in children with nonprimary lung disorders, for example collagen vascular diseases, inflammatory bowel diseases, or liver diseases.

\section{Pulmonary function testing}

Although lung function testing does not provide specific information, it represents a useful tool for both the diagnosis and the management of ILD in conjunction with other studies $[52,53]$. Generally, in ILD, pulmonary function abnormalities reflect a restrictive ventilatory defect with reduced lung compliance and decreased lung volumes [52-56]. Vital capacity (VC) is variably diminished; the decrease in total 
lung capacity (TLC), in general, is relatively less than in VC. Functional residual capacity (FRC) is also reduced but relatively less than VC and TLC, and residual volume (RV) is, generally, preserved; thus, the ratios of FRC/TLC and RV/ TLC are often increased. Airway involvement occurs only in a minority of patients [52].

The majority of patients show hypoxaemia as defined by a reduced resting arterial oxygen saturation $\left(\mathrm{Sa}, \mathrm{O}_{2}\right)$ or a reduced resting arterial oxygen tension and an increased alveolar-arterial oxygen tension gradient $\left(A \mathrm{a}, \mathrm{DO}_{2}\right)$ under room air [52]. Hypercarbia occurs only late in the disease course. DCO or transfer factor is often markedly reduced and may be abnormal before any other radiological or physiological findings. However, DCO corrected for lung volume may also be normal in many children. During exercise the above described dysfunctions become even more pronounced. Thus, gas exchange during exercise might be a more consistent and sensitive indicator of early disease. As yet, this has not been well studied in children; however, lung function changes in children with ILD have been reported to be similar to those observed in adults. In adults with ILD, measurements of VC strongly correlate with most static lung volumes and with $D C O$. Recently, it was suggested that standard lung function tests, such as VC and TLC, may yield more useful information than other extensive tests [57, 58].

The pulmonary function tests that can be performed in children with ILD depend on the age of the patient. In the age group 0-2 yrs, at least pulse oximetry and blood gas analysis (arterial or arterialised blood) with measurements of partial pressure of oxygen, partial pressure of carbon dioxide, and $A$ a, $\mathrm{DO}_{2}$ (only in arterial blood) should be performed at room air. FRC can be determined by body plethysmography or by gas dilution techniques. In the age group 2-6 yrs, pulse oximetry and blood gas analysis should be done at room air at rest. In addition, $\mathrm{Sa}_{2} \mathrm{O}_{2}$ and/or blood gases may also be determined during exercise. Some cooperative children may perform spirometry. In children aged $\geqslant 6 \mathrm{yrs}$, spirometry with registration of volume-time and flow-volume curve parameters can be performed. Lung volumes should be determined by body plethysmography or by gas dilution techniques. Similar to the younger age groups, pulse oximetry and blood gas analysis should be done at room air at rest and during exercise (e.g. cycle ergometer, treadmill, etc.). Whenever possible, assessment of DCO should be performed; measurement of lung compliance is optional. In all patients, pulmonary function tests are part of the diagnostic workup, as well as of the follow-up to evaluate the response to therapy.

\section{Tissues biopsies}

Histological evaluation of lung tissue usually represents the final step in a series of diagnostic methods. With increasing recognition of the different patterns of ILD and their clinical significance, histological investigation has become increasingly important.

Biopsy is desirable whenever there is clinical uncertainty, which often relates to an atypical clinical presentation. In practice, only a minority of children with suspected ILD require a biopsy, those usually having either idiopathic disorders or ILD unique to infancy (see below). However, diagnosis can be confirmed by the biopsy of other more accessible organs (e.g. skin biopsy in sarcoidosis). ILD is frequently patchy and it is, therefore, essential that representative areas are sampled. HRCT scanning provides a reliable guide in this respect, directing the surgeon to areas with active disease and avoiding those where the process is burnt-out. Taking multiple biopsies is recommended in adults, although it is uncertain how practical this is in children [59].

Different methods have been used for obtaining lung tissue both in adults and in children. The major difference between individual methods lies mainly in balancing invasiveness against the potential for obtaining adequate and sufficient tissue for diagnosis. The techniques of choice are OLB and VATB. For the other methods, transbronchial lung biopsy and percutaneous needle lung biopsy, their role in appropriate diagnosis and classification of paediatric patients with ILD, has yet to be established [60-62]. OLB usually provides sufficient tissue. In adults, OLB carries a low risk of morbidity $(<3 \%)$ and mortality $(<1 \%)$ and provides a specific diagnosis in a high proportion of patients [63]. In children, OLB can also provide a specific histological diagnosis in a high proportion of patients $(93 \%)$ and help initiate or change management $(56 \%)$, with few complications related directly to the biopsy procedure $(11 \%)$ [9]. In another study of children with ILD, a specific diagnosis was provided by OLB in $53 \%$, but there was a lower diagnostic yield in children aged $<2$ yrs [59]. The risk of the procedure lies not in the surgical procedure itself, but mainly in the underlying overall condition of the patient so the risk/benefit ratio should always be thoroughly considered and discussed with the child's parent or guardian [64].

As an alternative to OLB, a number of centres now use VATB. It has been shown that the procedure itself can be safely performed, even in small children [65, 66]. In 36 consecutive cases of paediatric lung disease (ILD in 27 cases, presumed metastatic lesions in five cases, and cavitary lesions in four cases), histological diagnosis was obtained in $97 \%$, therapy was directly affected in $83 \%$ and there were no postoperative complications. In a study comparing the value of VATB and OLB in 30 immunocompetent children with diffuse infiltrates, a specific diagnosis was reached in $60 \%$ using VATB and 53\% using OLB, complications being comparable [59].

Tissue should be sent fresh for microbiology and histopathology investigations. Most tissues need to be fixed in formalin for histological and immunohistochemical analysis; it is also recommended that a specimen portion be frozen and another preserved for electron microscopy. If at all possible, some material should be stored for research purposes, with appropriate prior informed consent and ethical approval from the parent or guardian.

\section{Histopathological approach}

Compared with adults, ILD is poorly understood and characterised in children. No classification of paediatric ILD is entirely satisfactory, although FAN et al. [18] provides a useful diagnostic grouping: 1) ILD of known aetiology; 2) ILD of unknown aetiology; and 3) ILD unique to infancy. In general, the ILDs of known aetiology, namely aspiration, infection, bronchopulmonary dysplasia, hypersensitivity pneumonia and lipid storage diseases, are diagnosed without biopsy. Most biopsies derive from groups 2 and 3 and several are classified histologically as patterns of interstitial pneumonia. Group 2 also includes disorders such as sarcoidosis. In adults, a consensus classification system for interstitial pneumonias has recently been proposed [67, 68] and modification of this system seems the most appropriate method for classifying such diseases in children, although the spectrum and frequency of disorders that account for these patterns differs (fig. 2). 


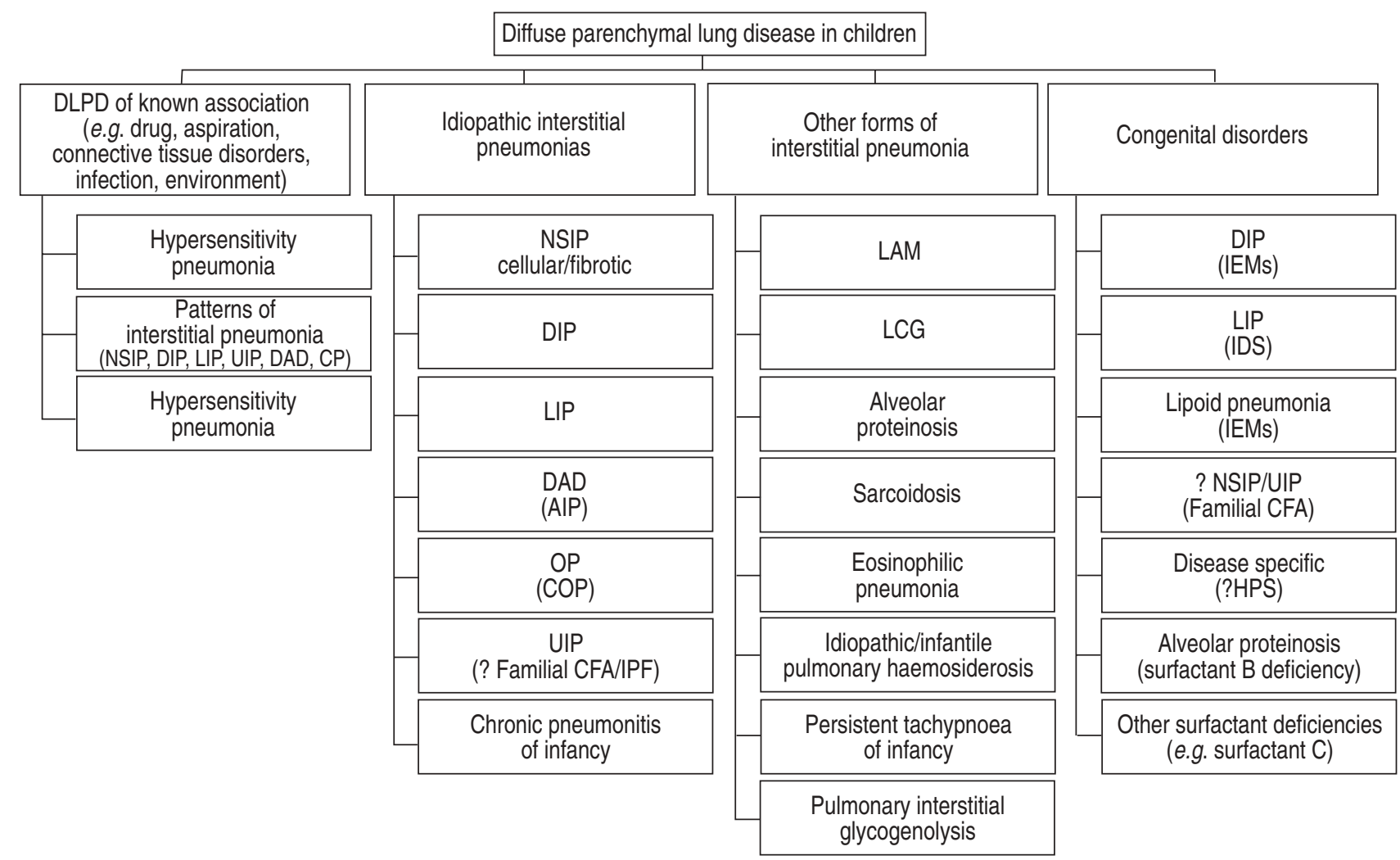

Fig. 2. - Histopathological classification of ILD in children. DLPD: diffuse lung parenchymal diseases in children; NSIP: nonspecific interstitial pneumonia; DIP: desquamative interstitial pneumonia; LIP: lymphocytic interstitial pneumonia; UIP: usual interstitial pneumonia; DAD: diffuse alveolar damage; CP: chronic pneumonitis; AIP: alveolar interstitial pneumonia; OP: organising pneumonia; COP: cryptogenic organising pneumonia, CFA: cryptogenic fibrosing alveolitis; IPF: idiopathic pulmonary fibrosis; LAM: lymphangioleiomyomatosis; LCG: langerhans cell granulomatosis; IEM: inborn errors of metabolism; IDS: immunodeficiency syndrome; HPS: hermansky-Pudlak syndrome.

Interstitial lung diseases of unknown aetiology. Cryptogenic fibrosing alveolitis, usual interstitial pneumonia and nonspecific interstitial pneumonia. Several groups describe series of children with cryptogenic fibrosing alveolitis (CFA), but most do not divide their cases into the recently described histopathological patterns of interstitial pneumonia. Nearly all series pre-date recognition of nonspecific interstitial pneumonia (NSIP). When strict histopathological criteria are applied, UIP is exceptionally rare in children. Today, most reported cases of CFA in children would probably be otherwise classified [7, 69]. This may explain why what has been termed "CFA in children" has a much better prognosis than CFA in adults. Most such cases are more appropriately classified as NSIP, although this pattern is currently poorly characterised in children.

Desquamative interstitial pneumonia. In adults, DIP is a comparatively rare form of ILD. It overlaps histologically with respiratory bronchiolitis-associated interstitial lung disease (RB-ILD), and smoking is currently believed to be the predominant cause [70]. RB-ILD appears to be limited to adults, but DIP is well described in children. The histological features (an accumulation of AM accompanied by a mild chronic interstitial pneumonia and at most mild interstitial fibrosis), are similar to those in adults but the outcome is worse in children, especially in infancy and those with familial disease [71, 72]. Therefore, the aetiology is probably different in children and most likely multifactorial. Some children with a DIP-like pattern have been shown to have surfactant B deficiency. Others have had lipid storage diseases and it has been suggested that hitherto unrecognised defects in metabolism may be responsible for other cases [73].
Lymphocytic interstitial pneumonia. LIP is characterised by a marked diffuse infiltrate of mature lymphocytes, plasma cells and histiocytes within the pulmonary interstitium, particularly the alveolar walls. Histologically, it overlaps with follicular bronchiolitis, these two patterns of disease together comprising a spectrum of reactive pulmonary lymphoid hyperplasia. LIP is nearly always associated with either connective tissue disorders or immunodeficiency states, both congenital and acquired. It is a well described complication of paediatric AIDS and occurs in $>30 \%$ of children perinatally affected by HIV. Familial cases are also described [74].

Organising pneumonia. Organising pneumonia (OP) is characterised by intra-alveolar buds of granulation tissue and although largely sparing the pulmonary interstitium, it can mimic ILD clinically and radiologically. Rare cases have been reported in children. The histopathologist needs to exclude an underlying process masked by the OP, such as Langerhans cell granulomatosis, and alert the clinician to the wide differential diagnosis associated with this pattern of disease, before issuing a report of cryptogenic OP.

Diffuse alveolar damage. Diffuse alveolar damage (DAD) is the histopathological pattern seen in both adult and infantile respiratory distress syndromes, but few infants require a biopsy. Occasional cases of acute respiratory failure develop in previously healthy older children, with DAD on biopsy, and if no underlying cause can be identified, a clinicopathological diagnosis of acute interstitial pneumonia is appropriate [75]. 
Interstitial lung disease unique to infancy. This category includes cellular intersititial pneumonitis of infants, chronic pneumonitis of infancy, familial DIP, IPF of infancy, infantile pulmonary haemosiderosis, surfactant protein (SP) B deficiency and persistent tachypnoea of infancy. Cellular intersititial pneumonitis of infants appears histologically similar to nonspecific interstitial pneumonia in adults [76]. Chronic pneumonitis of infancy has a distinct histological pattern showing florid type 2 cell hyperplasia and diffuse expansion of the interstitium by fibroblastic tissue with comparatively little inflammation [74, 75, 77]. Acellular intra-alveolar material resembling that seen in alveolar proteinosis is a frequent finding. The aetiology is unknown. Persistent tachypnoea of infancy is a recently described mild form of ILD of uncertain aetiology. Histological abnormalities are minimal, although neuroendocrine cell hyperplasia has been reported and these findings in the correct clinical context should therefore prompt consideration of this diagnosis [78]. SP C gene mutation is also associated with development of familial pulmonary fibrosis, with patterns of UIP, DIP and cellular NSIP being described [79]. Pulmonary interstitial glycogenosis has also recently been described in neonates. It is thought to represent a maturation defect of interstitial cells that leads them accumulating glycogen within their cytoplasm. Most cases have had a favourable prognosis [80]. Its relationship to histological patterns, such as cellular interstitial pneumonia, remains uncertain.

Systemic disorders with pulmonary involvement. This group includes the connective tissue disorders, malignancies presenting as ILD and Langerhans cell histiocytosis. The latter two are generally diagnosed on their characteristic clinical and histopathological features, whilst patients with pulmonary involvement by connective tissue disorders generally present with NSIP or LIP in children, or less commonly UIP, OP or DAD. It should be noted that pulmonary disease may precede the systemic manifestations of a connective tissue disorder.

It is clear that for any given situation multidisciplinary meetings between clinicians, histopathologists and radiologists should be engaged to discuss and bring together the various aspects of the case into a final working diagnosis from which a treatment plan is then designed for the individual patient.

\section{Treatment strategies}

The treatment of ILD in children is complicated because of the large differential diagnosis of underlying conditions that can produce this pathology. In addition, ILD is rare in children, which makes the organisation and analysis of controlled trials of specific treatments extremely difficult. Consequently, most current regimes are based on experience gained in a small number of cases within individual centres. The natural history of the disease is very variable and some cases burn out spontaneously even without treatment, whilst others progress relentlessly towards a fatal outcome despite all treatment modalities given [68, 81].

Few children require no treatment and recover spontaneously. However, most require $\mathrm{O}_{2}$ therapy based on day and night time $\mathrm{Sa}, \mathrm{O}_{2}$ levels, and specific medications. Oral prednisolone $\left(1-2 \mathrm{mg} \cdot \mathrm{kg}^{-1} \cdot \mathrm{day}^{-1}\right)$ or pulsed intravenous methylprednisolone, singly or in combination with hydroxychloroquine, are the most commonly used drug treatments [2, 4]. Children with significant disease are best treated with pulsed methylprednisolone at least initially [11]. This is usually given at a dose of $10-30 \mathrm{mg} \cdot \mathrm{kg}^{-1} \cdot \mathrm{day}^{-1}$ for 3 days consecutively at monthly intervals. The minimum number of cycles recommended is three, but treatment may need to be continued for $\geqslant 6$ months depending on response. When the disease is under control, the dosage of methylprednisolone can be reduced or the time between cycles can be spaced out. The disease may then be controlled with oral prednisolone preferably given as an alternate day regime. In a few cases oral prednisolone is used from the beginning simultaneously with intravenous methylprednisolone but this should only be required in those with very severe disease. Methylprednisolone sometimes works even when other steroids fail $[11,82]$.

Cases in which the disease is mild and where the biopsy shows largely fibrotic change can be treated with hydroxychloroquine $\left(6-10 \mathrm{mg} \cdot \mathrm{kg}^{-1} \cdot \mathrm{day}^{-1}\right.$ in two divided doses) alone. Individual case reports have described a response to chloroquine even in the presence of steroid resistance $[83,84]$. Currently, hydroxychloroquine is the preferred agent as it is less toxic than chloroquine. The decision as to which agent to use is based on the lung biopsy findings. If there is a large amount of desquamation and inflammation present then it is preferable to use steroids. Where collagen is present in increased amounts representing pre-fibrotic change, then hydroxychloroquine alone is recommended. Those with severe changes will require both agents. However, in all situations, the aim of treatment is to titrate the medication, particularly steroids, to the lowest dose compatible with clinical stability and to avoid breakthrough of symptoms whenever possible.

Other treatments include immunosuppressive agents, such as azathioprine $\left(2-3 \mathrm{mg} \cdot \mathrm{kg}^{-1} \cdot \mathrm{day}^{-1}\right)$, cyclosphosphamide $\left(1-1.5 \mathrm{mg} \cdot \mathrm{kg}^{-1} \cdot \mathrm{day}^{-1}\right)$, cyclosporin $\left(6 \mathrm{mg} \cdot \mathrm{kg}^{-1} \cdot \mathrm{day}^{-1}\right)$ or methotrexate $\left(2.5-7.5 \mathrm{mg} \cdot \mathrm{kg}^{-1} \cdot \mathrm{week}^{-1}\right)$. Lung or heart-lung transplantation is a viable option even at aged $<10$ yrs. Several situations may require specific therapeutic strategies. In pulmonary alveolar proteinosis, whole lung lavage can be effective by removing the material from the alveolar space [41]. Treatment with GM-CSF has also been used [85, 86].

It is important to stress that in all situations, maintenance of nutrition with an adequate energy intake is extremely important in the management of children with ILD. Immunisation with influenza vaccine on an annual basis is recommended along with other routine immunisations against major respiratory pathogens.

A favourable response to treatment can be judged along similar lines to those quoted for adult disease [81]. The patient should be assessed at regular intervals of 3-6 months or more frequently if severely ill. Improvement is judged by decreased breathlessness or cough, increase in $\mathrm{Sa}_{\mathrm{a}} \mathrm{O}_{2}$ at rest of $2-4 \%$, and changes in pulmonary function tests. Improvements on chest radiograph and HRCT scan may also be seen, but these tend to occur over a much longer period of time of 2-4 yrs. Studies in children have not shown a good correlation between histological findings and outcome [52, 68]. Some children with relatively severe fibrosis on biopsy make good progress, whereas others with mild desquamation have a poor outcome. This is probably due to the variable severity of the disease in different parts of the lung, especially in relation to the particular area biopsied, despite ultrasound or HRCT guidance. Overall, a favourable response to corticosteroid therapy can be expected in $40-65 \%$ of cases of idiopathic interstitial pneumonitis [68]. The outcome for infants is more variable. Although patients in this age group can have a significant mortality [11], others have reported a relatively good outcome [85]. Other treatments which may be considered in the future include the use of macrolide antibiotics or very small particle chlorofluorocarbon-free inhaled steroids as anti-inflammatory agents. 


\section{New insights into ILD pathophysiology in children}

There is increasing evidence that expression and outcome of ILD in children differs from adult ILD, with childhood pathologies having a more favourable response to immunosuppressive therapies. This suggests that the pathogenic mechanisms involved may have age specificity, and that additional events related to lung growth and maturation could play a critical role in the disease progression. In addition, the pathogenesis of childhood ILD, perhaps to a greater extent than adult disease, is likely to have significant genetic influences. Identification of the genes involved in childhood ILD will undoubtedly enhance both the understanding of the biology of these conditions and also provide new therapeutic targets for both childhood and adult disease, a prize clearly worth pursuing.

\section{Genetic factors in childhood ILD}

Genetic variation is likely to modulate susceptibility, progression and therapeutic response in children with ILD. The relatively high incidence of a family history in childhood cases suggests a major genetic determinant, at least in some individuals. However, in the majority of cases, geneenvironment interactions involving multiple genetic loci will determine disease development and outcome. Evidence for a genetic influence in the development of ILD includes the marked variation in response to injurious agents in both humans and animal models despite similar levels of exposure, and the existence of familial forms [87-90]. A number of studies in adults and children with IPF report the familial clustering of cases including cases reported in twins and family members separated from an early age [91, 92]. Such cases appear histologically indistinguishable from the nonfamilial forms, suggesting shared pathogenic pathways. Rarer familial forms, well documented in the literature, include the Hermansky-Pudlak syndrome (HPS) and familial hypercalcaemic hypocalcuria (FHH), [93, 94]. Their relevance to other forms of childhood ILD is unclear, but it is possible that these syndromes share common genetic influences with other forms of ILD. A linkage with a mutation in the SP C gene in children with familial ILD has recently been reported but requires further validation $[95,96]$.

In the design of genetic studies, one must consider the appropriate genetic methodology, the acquisition of study populations of appropriate size for statistical power, the influence of ethnic diversity on allele frequency, the need for detailed phenotypic data (clinical, biochemical or histopathological indices of disease or biological activity), and the use of appropriate comparison populations. Two main methodological approaches are employed. Genome-wide approaches require related individuals in whom the phenotype can be accurately established, and in both HPS and FHH, the relevant genes have been identified by such an approach [97, 98]. The other main approach is a "candidate gene" approach, with the studies of known or novel polymorphisms in genes that are purported to play a role in disease pathogenesis, and is suitable for unrelated individuals. In adults with IPF, a number of candidate genes have been studied including genes encoding the interleukin (IL)-1 family, ACE, tumour necrosis factor-alpha, IL-6 and the human leukocyte antigen (HLA) system. The strongest correlation has been described by BRIGGS et al. [99] between HLA DR3/DRw52a and the susceptibility of patients with systemic sclerosis to develop pulmonary fibrosis. In children, to date, only SP polymorphisms have received attention in the context of respiratory distress syndrome, but are worthy of mention as strong candidates for ILD. An initial observation by KALA et al. [100] suggested a possible association with the 1A0 SP-A allele and SP-B variant. HAATAJA et al. [101] showed no association with SP-B polymorphisms. However, many of the SP alleles are in linkage disequilibrium, and thus should be studied together, rather than in isolation. These studies also highlight important racial differences in allele frequency [102].

\section{Concepts of ILD pathogenesis in children and implication for treatment strategies}

A widely held view has been that all fibrotic lung diseases share common pathogenetic features, regardless of initiating agent. Largely based on adult research data, a hypothesis of persistent interstitial inflammation leading to, and modulating development of, fibrosis has emerged. In response to injury, an inflammatory response or alveolitis is invoked, which features recruitment of inflammatory and immunoregulatory cells into the interstitium, alveolar walls and perialveolar tissues. This inflammatory infiltrate, alone or in concert with varying degrees of fibrosis, can lead to a thickened alveolar wall, the histological marker of paediatric ILD. Persistence of this response will eventually lead to extensive end-stage fibrosis with loss of alveolar gas-exchange function.

However, recent investigations have provided data supporting the view that inflammation is not prominent [103-105]. Accordingly, the latest revised hypothesis for fibrogenesis proposes that chronic ILD represents a model of abnormal wound healing, resulting from multiple, microscopic sites of ongoing alveolar epithelial cell injury and activation, with release of fibrogenic mediators. These lead to the appearance of fibroblast-myofibroblast foci within the lung interstitium (identifiable on lung tissue biopsies); possibly reflecting local sites of injury and abnormal repair characterised by fibroblast-myofibroblast migration and proliferation, decreased myofibroblast apoptosis, and enhanced release of, and response to, fibrogenic growth factors. The extent of these foci appears to predict outcome/survival in ILD [106]. Following injury, rapid re-epithelialisation is essential to the restoration of barrier integrity and requires epithelial cell migration, proliferation and differentiation of type II into type I alveolar epithelial cells. In ILD, the excessive loss of alveolar epithelial cells by apoptosis may seriously compromise the ability of type II alveolar epithelial cells to carry this out. In parallel, proliferating fibroblasts emerging during the normal repair process are able to selfregulate their production of matrix synthesis and degradation components and mitogens, through mediator-driven autocrine mechanisms. This may be deregulated in established fibrosis by an increased number of cells displaying an altered profibrotic myofibroblast-like phenotype. Alveolar epithelial proliferation is dependent on the availability of several growth factors including insulin-like growth factor, keratinocyte growth factor, hepatocyte growth factor and plateletderived growth factor $[107,108]$. During childhood and in the context of lung growth and development, it is strongly suggested that the programmed production of some of these mitogenic factors may promote the process of reepithelialisation, and, consequently, may help counteract the altered secretion of mediators involved in migration and proliferation of fibroblasts, as well as in differentiation into myofibroblasts. Clearly, this hypothesis needs to be further investigated.

A number of novel therapeutic approaches have emerged for consideration as a result of increased knowledge of ILD pathogenesis $[1,2,103]$. Several of these have shown promise 
at the clinical trial stage with adult IPF patients. Encouraging preliminary results have been obtained with interferon- $\gamma$ [109]. Beneficial antifibrotic effects have also been reported for other molecules, such as pirfenidone [110]. Applying postgenomic approaches to understanding the molecular basis of ILD pathogenesis in children should help identify important preclinical markers of disease, pathways of disease regulation, and novel potential targets for therapeutic intervention.

\section{Conclusion}

The large population of children (185 patients) with a diagnosis of chronic interstitial lung diseases collected through the European Respiratory Society Task Force on chronic interstitial lung diseases in immunocompetent children has provided important clinically-relevant information on the current approach to diagnosis and management of chronic paediatric interstitial lung diseases. The main conclusion was that major variations exist between the various centres regarding disease classification and evaluation, and that standardisations are needed. In this view, the multidisciplinary team of expert paediatric and adult physicians, as well as basic scientists included in the Task Force, has led to establish multicentre collaborations. This represents an essential step to define reliable and homogeneous phenotypic characteristics of the patients, to draw up recommendations to practicing clinicians for the everyday care of children with interstitial lung diseases, and to provide new insights into the pathophysiology of interstitial lung diseases in children through carefully selected research programmes.

\section{References}

1. Gross TJ, Hunninghake GW. Idiopathic pulmonary fibrosis. $N$ Engl J Med 2001; 345: 517-525.

2. Fan L, Langston C. Paediatric interstitial lung disease. Am J Respir Crit Care Med 2002; 165: 1466-1467.

3. Fan LL, Mullen AL, Brugman SM, Inscore SC, Parks DP, White CW. Clinical spectrum of chronic interstitial lung disease in children. J Pediatr 1992; 121: 867-872.

4. Fan LL, Langston C. Chronic interstitial lung disease in children. Pediatr Pulmonol 1993; 16: 184-196.

5. Bokulic RE, Hilman BC. Interstitial lung disease in children. Pediatr Clin North Am 1994; 41: 543-567.

6. Hilman BC. Diagnosis and treatment of ILD. Pediatr Pulmonol 1997; 23: 1-7.

7. Katzenstein AL, Myers JL. Idiopathic pulmonary fibrosis: clinical relevance of pathologic classification. Am J Respir Crit Care Med 1998; 157: 1301-1315.

8. Coultas DB, Zumwalt RE, Black WC, Sobonya RE. The epidemiology of interstitial lung diseases. Am J Respir Crit Care Med 1994; 150: 967-972.

9. Coren ME, Nicholson AG, Goldstraw P, Rosenthal M, Bush A. Open lung biopsy for diffuse interstitial lung disease in children. Eur Respir J 1999; 14: 817-821.

10. Desmarquest $\mathrm{P}$, Tamalet A, Fauroux B, et al. Chronic interstitial lung disease in children: response to high-dose intravenous methylprednisolone pulses. Pediatr Pulmonol 1998; 26: 332-338.

11. Osika E, Muller MH, Boccon-Gibod L, et al. Idiopathic pulmonary fibrosis in infants. Pediatr Pulmonol 1997; 23: 4954.

12. Howenstine MS, Eigen H. Current concepts on interstitial lung disease in children. Curr Opin Pediatr 1999; 11: 200-204.

13. Fan LL, Kozinetz CA, Deterding RR, Brugman SM. Evaluation of a diagnostic approach to paediatric interstitial lung disease. Paediatrics 1998; 101: 82-85.

14. Pinsker KL, Schneyer B, Becker N, Kamholz SL. Usual interstitial pneumonia following Texas A2 influenza infection. Chest 1981; 80: 123-126.

15. Kuwano K, Nomoto Y, Kunitake R, et al. Detection of adenovirus E1A DNA in pulmonary fibrosis using nested polymerase chain reaction. Eur Respir J 1997; 10: 14451449.

16. Diehl JL, Gisselbrecht M, Meyer G, Israel-Biet D, Sors H. Bronchiolitis obliterans organizing pneumonia associated with chlamydial infection. Eur Respir J 1996; 9: 13201322.

17. Llibre JM, Urban A, Garcia E, Carrasco MA, Murcia C. Bronchiolitis obliterans organizing pneumonia associated with acute Mycoplasma pneumoniae infection. Clin Infect Dis 1997; 25: 1340-1342.

18. Pfleger A, Eber E, Popper H, Zach MS. Chronic interstitial lung disease due to Epstein-Barr virus infection in two infants. Eur Respir J 2000; 15: 803-806.

19. Rodriguez de Castro F, Carrillo T, Castillo R, Blanco C, Diaz F, Cuevas M. Relationships between characteristics of exposure to pigeon antigens. Clinical manifestations and humoral immune response. Chest 1993; 103: 1059-1063.

20. Border WA, Baehler RW, Bhathena D, Glassock RJ. IgA antibasement membrane nephritis with pulmonary hemorrhage. Ann Intern Med 1979; 91: 21-25.

21. Davenport A, Lock RJ, Wallington TB. Clinical relevance of testing for antineutrophil cytoplasm antibodies (ANCA) with a standard indirect immunofluorescence ANCA test in patients with upper or lower respiratory tract symptoms. Thorax 1994; 49: 213-217.

22. Ginzler EM. Clinical manifestations of disease activity, its measurement, and associated morbidity in systemic lupus erythematosus. Curr Opin Rheumatol 1991; 3: 780-788.

23. Heiner DC, Sears JW, Kniker WT. Multiple precipitins to cow's milk in chronic respiratory diseases. Am J Dis Child 1962; 52: 822-825.

24. Stafford HA, Polmar SH, Boat TF. Immunologic studies in cow's milk-induced pulmonary hemosiderosis. Pediatr Res 1977; 11: 898-903.

25. Rodriguez GE, Shin BC, Abernathy RS, et al. Serum angiotensin-converting enzyme activity in normal children and in those with sarcoidosis. J Pediatr 1981; 99: 68-72.

26. Beneteau-Burnat B, Baudin B, Morgant G, Baumann FC, Giboudeau J. Serum angiotensin-converting enzyme in healthy and sarcoidotic children: comparison with the reference interval for adults. Clin Chem 1990; 36: 344-346.

27. Seely JM, Effmann EL, Muller NL. High-resolution CT of paediatric lung disease: imaging findings. $A J R \quad A m$ J Roentgenol 1997; 168: 1269-1275.

28. Lynch DA, Hay T, Newell JD Jr, Divgi VD, Fan LL. Paediatric diffuse lung disease: diagnosis and classification using high-resolution CT. AJR Am J Roentgenol 1999; 173: 713-718.

29. Copley SJ, Padley SP. High-resolution CT of paediatric lung disease. Eur Radiol 2001; 11: 2564-2575.

30. Copley SJ, Coren M, Nicholson AG, Rubens MB, Bush A, Hansell DM. Diagnostic accuracy of thin-section CT and chest radiography of paediatric interstitial lung disease. $A J R$ Am J Roentgenol 2000; 174: 549-554.

31. Murata K, Khan A, Rojas KA, Herman PG. Optimization of computed tomography technique to demonstrate the fine structure of the lung. Invest Radiol 1988; 23: 170-175.

32. Ambrosino MM, Genieser NB, Roche KJ, Kaul A, Lawrence RM. Feasibility of high-resolution, low-dose chest CT in evaluating the paediatric chest. Pediatr Radiol 1994; 24: 6-10.

33. Lucaya $J$, Piqueras $J$, Garcia-Pena $P$, Enriquez $G$, Garcia-Macias M, Sotil J. Low-dose high-resolution CT of the chest in children and young adults: dose, cooperation, artefact incidence, and image quality. AJR Am J Roentgenol 2000; 175: 985-992.

34. American Academy of Paediatrics Committee on Drugs: Guidelines for monitoring and management of paediatric 
patients during and after sedation for diagnostic and therapeutic procedures. Paediatrics 1992; 89: 1110-1115.

35. Austin JH, Muller NL, Friedman PJ, et al. Glossary of terms for CT of the lungs: recommendations of the Nomenclature Committee of the Fleischner Society. Radiology 1996; 200: 327-331.

36. Schmidt H, Lorcher U, Kitz R, Zielen S, Ahrens P, Konig R. Pulmonary alveolar microlithiasis in children. Pediatr Radiol 1996; 26: 33-36.

37. Koh DM, Hansell DM. Computed tomography of diffuse interstitial lung disease in children. Clin Radiol 2000; 55: 659667.

38. Albafouille V, Sayegh N, De Coudenhove S, et al. CT scan patterns of pulmonary alveolar proteinosis in children. Pediatr Radiol 1999; 29: 147-152.

39. Leung AN, Miller RR, Muller NL. Parenchymal opacification in chronic infiltrative lung diseases: CT-pathologic correlation. Radiology 1993; 188: 209-214.

40. Remy-Jardin M, Giraud F, Remy J, Copin MC, Gosselin B, Duhamel A. Importance of ground-glass attenuation in chronic diffuse infiltrative lung disease: pathologic-CT correlation. Radiology 1993; 189: 693-698.

41. de Blic J, Midulla F, Barbato A, et al. Bronchoalveolar lavage in children. ERS Task Force on bronchoalveolar lavage in children. European Respiratory Society. Eur Respir $J$ 2000; 15: 217-231.

42. Tessier V, Chadelat K, Baculard A, Housset B, Clement A. BAL in children: a controlled study of differential cytology and cytokine expression profiles by alveolar cells in paediatric sarcoidosis. Chest 1996; 109: 1430-1438.

43. Ronchetti R, Midulla F, Sandstrom T, et al. Bronchoalveolar lavage in children with chronic diffuse parenchymal lung disease. Pediatr Pulmonol 1999; 27: 395-402.

44. Tredano M, De Blic J, Griese M, Fournet JC, Elion J, Bahuau M. Clinical biological and genetic heterogeneity of the inborn errors of pulmonary surfactant metabolism. Clin Chem Lab Med 2001; 39: 90-108.

45. Grebski E, Hess T, Hold G, Speich R, Russi E. Diagnostic value of hemosiderin-containing macrophages in bronchoalveolar lavage. Chest 1992; 102: 1794-1799.

46. Refabert L, Rambaud C, Mamou-Mani T, Scheinmann P, de Blic J. Cdla-positive cells in bronchoalveolar lavage samples from children with Langerhans cell histiocytosis. J Pediatr 1996; 129: 913-915.

47. Tabak L, Yilmazbayhan D, Kilicaslan Z, Tascioglu C, Agan M. Value of bronchoalveolar lavage in lipidoses with pulmonary involvement. Eur Respir J 1994; 7: 409-411.

48. Midulla F, Strappini PM, Ascoli V, et al. Bronchoalveolar lavage cell analysis in a child with chronic lipid pneumonia. Eur Respir J 1998; 11: 239-242.

49. Knauer-Fischer S, Ratjen F. Lipid-laden macrophages in bronchoalveolar lavage fluid as a marker for pulmonary aspiration. Pediatr Pulmonol 1999; 27: 419-422.

50. Ratjen F, Costabel U, Griese M, Paul K. Bronchoalveolar lavage fluid findings in children with hypersensitivity pneumonitis. Eur Respir J 2003; 21: 144-148.

51. Oermann CM, Panesar KS, Langston C, et al. Pulmonary infiltrates with eosinophilia syndromes in children. J Pediatr 2000; 136: 351-358.

52. Sharief N, Crawford OF, Dinwiddie R. Fibrosing alveolitis and desquamative interstitial pneumonitis. Pediatr Pulmonol 1994; 17: 359-365.

53. Kerem E, Bentur L, England S, et al. Sequential pulmonary function measurements during treatment of infantile chronic interstitial pneumonitis. J Pediatr 1990; 116: 61-67.

54. Gaultier C, Chaussain M, Boule M, et al. Lung function in interstitial lung diseases in children. Bull Physiopathol Respir (Nancy) 1980; 16: 57-66.

55. Zapletal A, Houstek J, Samanek M, Copova M, Paul T. Lung function in children and adolescents with idiopathic interstitial pulmonary fibrosis. Pediatr Pulmonol 1985; 1: 154-166.
56. Steinkamp G, Muller KM, Schirg E, von der Hardt H Fibrosing alveolitis in childhood. A long-term follow-up. Acta Paediatr Scand 1990; 79: 823-831.

57. Javaheri S, Sicilian L. Lung function, breathing pattern, and gas exchange in interstitial lung disease. Thorax 1992; 47: 93 97.

58. Erbes R, Schaberg T, Loddenkemper R. Lung function tests in patients with idiopathic pulmonary fibrosis. Are they helpful for predicting outcome? Chest 1997; 111: 51-57.

59. Fan LL, Kozinetz CA, Wojtczak HA, Chatfield BA, Cohen $\mathrm{AH}$, Rothenberg SS. Diagnostic value of transbronchial, thoracoscopic, and open lung biopsy in immunocompetent children with chronic interstitial lung disease. J Pediatr 1997; 131: 565-569.

60. Smyth RL, Carty H, Thomas H, van Velzen D, Heaf D. Diagnosis of interstitial lung disease by a percutaneous lung biopsy sample. Arch Dis Child 1994; 70: 143-144.

61. Spencer DA, Alton HM, Raafat F, Weller PH. Combined percutaneous lung biopsy and high-resolution computed tomography in the diagnosis and management of lung disease in children. Pediatr Pulmonol 1996; 22: 111-116.

62. Whitehead B, Scott JP, Helms P, et al. Technique and use of transbronchial biopsy in children and adolescents. Pediatr Pulmonol 1992; 12: 240-246.

63. Gaensler EA, Carrington CB. Open biopsy for chronic diffuse infiltrative lung disease: clinical, roentgenographic, and physiological correlations in 502 patients. Ann Thorac Surg 1980; 30: 411-426.

64. Kramer MR, Berkman N, Mintz B, Godfrey S, Saute M, Amir G. The role of open lung biopsy in the management and outcome of patients with diffuse lung disease. Ann Thorac Surg 1998; 65: 198-202.

65. Rothenberg SS. Thoracoscopy in infants and children. Semin Pediatr Surg 1994; 3: 277-282.

66. Rothenberg SS, Wagner JS, Chang JH, Fan LL. The safety and efficacy of thoracoscopic lung biopsy for diagnosis and treatment in infants and children. J Pediatr Surg 1996; 31: 100-103; discussion 103-104.

67. American Thoracic Society/European Respiratory Society International Multidisciplinary Consensus Classification of the Idiopathic Interstitial Pneumonias. This joint statement of the American Thoracic Society (ATS), and the European Respiratory Society (ERS) was adopted by the ATS board of directors, June 2001 and by the ERS Executive Committee, June 2001. Am J Respir Crit Care Med 2002; 165: 277-304.

68. American Thoracic Society. Idiopathic pulmonary fibrosis: diagnosis and treatment. International consensus statement. American Thoracic Society (ATS), and the European Respiratory Society (ERS). Am J Respir Crit Care Med 2000; 161: 646-664.

69. Nicholson AG, Kim H, Corrin B, et al. The value of classifying interstitial pneumonitis in childhood according to defined histological patterns. Histopathology 1998; 33: 203211.

70. Ryu JH, Colby TV, Hartman TE, Vassallo R. Smokingrelated interstitial lung diseases: a concise review. Eur Respir $J$ 2001; 17: 122-132.

71. Stillwell PC, Norris DG, O'Connell EJ, Rosenow EC 3rd, Weiland LH, Harrison EG Jr. Desquamative interstitial pneumonitis in children. Chest 1980; 77: 165-171.

72. Tal A, Maor E, Bar-Ziv J, Gorodischer R. Fatal desquamative interstitial pneumonia in three infants siblings. $J$ Pediatr 1984; 104: 873-876.

73. Amir G, Ron N. Pulmonary pathology in Gaucher's disease. Hum Pathol 1999; 30: 666-670.

74. Nicholson AG. Lymphocytic interstitial pneumonia and other lymphoproliferative disorders. Sem Resp Crit Care Med 2001; 22: 409-422.

75. Katzenstein AL, Myers JL, Mazur MT. Acute interstitial pneumonia. A clinicopathologic, ultrastructural, and cell kinetic study. Am J Surg Pathol 1986; 10: 256-267.

76. Schroeder SA, Shannon DC, Mark EJ, Seidman CE, 
Seidman JG. Cellular interstitial pneumonitis in infants. A clinicopathologic study. Chest 1992; 101: 1065-1069.

77. Katzenstein AL, Gordon LP, Oliphant M, Swender PT. Chronic pneumonitis of infancy. A unique form of interstitial lung disease occurring in early childhood. Am J Surg Pathol 1995; 19: 439-447.

78. Resch B, Eber E, Zach M. Chronische interstitielle Lungenkrankungen in Kindersalter - ein Überblick. Klin Padiatr 1997; 209: 59-65.

79. Thomas AQ, Lane K, Phillips J 3rd, et al. Heterozygosity for a surfactant protein $\mathrm{C}$ gene mutation associated with usual interstitial pneumonitis and cellular nonspecific interstitial pneumonitis in one kindred. Am J Respir Crit Care Med 2002; 165: 1322-1328.

80. Canakis AM, Cutz E, Manson D, O'Brodovich $\mathrm{H}$. Pulmonary interstitial glycogenosis: a new variant of neonatal interstitial lung disease. Am J Respir Crit Care Med 2002; 165: 1557-1565.

81. Costabel U, King TE. International consensus statement on idiopathic pulmonary fibrosis. Eur Respir J 2001; 17: 163167.

82. Paul K, Klettke U, Moldenhauer J, et al. Increasing dose of methylprednisolone pulse therapy treats desquamative interstitial pneumonia in a child. Eur Respir $J$ 1999; 14: 14291432.

83. Balasubramanyan N, Murphy A, O'Sullivan J, O'Connell EJ. Familial interstitial lung disease in children: response to chloroquine treatment in one sibling with desquamative interstitial pneumonitis. Pediatr Pulmonol 1997; 23: 55-61.

84. Blyth C, Lane C. Hydroxychloroquine retinopathy: is screening necessary? BMJ 1998; 316: 716-717.

85. Hacking D, Smyth R, Shaw N, Kokia G, Carty H, Heaf D. Idiopathic pulmonary fibrosis in infants: good prognosis with conservative management. Arch Dis Child 2000; 83: 152-157.

86. Balfour-Lynn IM, Martin I, Whitehead BF, Rees PG, Elliott MJ, de Leval MR. Heart-lung transplantation for patients under 10 with cystic fibrosis. Arch Dis Child 1997; 76: 38-40.

87. Marshall RP, McAnulty RJ, Laurent GJ. The pathogenesis of pulmonary fibrosis: is there a fibrosis gene? Int $J$ Biochem Cell Biol 1997; 29: 107-120.

88. Marshall RP, Puddicombe A, Cookson WO, Laurent GJ. Adult familial cryptogenic fibrosing alveolitis in the United Kingdom. Thorax 2000; 55: 143-146.

89. Schrier DJ, Kunkel RG, Phan SH. The role of strain variation in murine bleomycin-induced pulmonary fibrosis. Am Rev Respir Dis 1983; 127: 63-66.

90. Tisdale JE, Follin SL, Ordelova A, Webb CR. Risk factors for the development of specific noncardiovascular adverse effects associated with amiodarone. J Clin Pharmacol 1995; 35: 351-356.

91. Peabody JW, Peabody JWJ, Hayes EW. Idiopathic pulmonary fibrosis: its occurrence in identical twin sisters. Dis Chest 1950; 18: 330.

92. Swaye P, Van Ordstrand HS, McCormack LJ, Wolpaw SE. Familial Hamman-Rich syndrome. Report of eight cases. Dis Chest 1969; 55: 7-12.

93. Hermansky F, Pudlak P. Albinism associated with hemorrhagic diathesis and unusual pigmented reticular cells in the bone marrow. Report of two cases with histochemical studies. Blood 1959; 14.
94. Auwerx J, Demedts M, Bouillon R, Desmet J. Coexistence of hypocalciuric hypercalcaemia and interstitial lung disease in a family: a cross-sectional study. Eur J Clin Invest 1985; 15: 6-14.

95. Nogee LM, Garnier G, Dietz HC, et al. A mutation in the surfactant protein $\mathrm{B}$ gene responsible for fatal neonatal respiratory disease in multiple kindreds. J Clin Invest 1994; 93: $1860-1863$.

96. Nogee LM, Dunbar AE 3rd, Wert SE, Askin F, Hamvas A, Whitsett JA. A mutation in the surfactant protein $\mathrm{C}$ gene associated with familial interstitial lung disease. $N$ Engl $J$ Med 2001; 344: 573-579.

97. Oh J, Bailin T, Fukai K, et al. Positional cloning of a gene for Hermansky-Pudlak syndrome, a disorder of cytoplasmic organelles. Nat Genet 1996; 14: 300-306.

98. Pollak MR, Brown EM, Chou YH, et al. Mutations in the human $\mathrm{Ca}(2+)$-sensing receptor gene cause familial hypocalciuric hypercalcemia and neonatal severe hyperparathyroidism. Cell 1993; 75: 1297-1303.

99. Briggs DC, Vaughan RW, Welsh KI, Myers A, duBois RM, Black CM. Immunogenetic prediction of pulmonary fibrosis in systemic sclerosis. Lancet 1991; 338: 661-662.

100. Kala P, Ten Have T, Nielsen H, Dunn M, Floros J. Association of pulmonary surfactant protein A (SP-A) gene and respiratory distress syndrome: interaction with SP-B. Pediatr Res 1998; 43: 169-177.

101. Haataja R, Ramet M, Marttila R, Hallman M. Surfactant proteins $\mathrm{A}$ and $\mathrm{B}$ as interactive genetic determinants of neonatal respiratory distress syndrome. Hum Mol Genet 2000; 9: 2751-2760.

102. Floros J, Fan R, Diangelo S, Guo X, Wert J, Luo J. Surfactant protein (SP) B associations and interactions with SP-A in white and black subjects with respiratory distress syndrome. Pediatr Int 2001; 43: 567-576.

103. Selman M, King TE, Pardo A. Idiopathic pulmonary fibrosis: prevailing and evolving hypotheses about its pathogenesis and implications for therapy. Ann Intern Med 2001; 134: 136-151.

104. Selman M, Pardo A. Idiopathic pulmonary fibrosis: an epithelial/fibroblastic cross-talk disorder. Respir Res 2002; 3: 3 .

105. Selman M, Pardo A. The epithelial/fibroblastic pathway in the pathogenesis of idiopathic pulmonary fibrosis: tying loose ends. Am J Respir Cell Mol Biol 2003; 29: S93-S98.

106. King TE Jr, Schwarz MI, Brown K, et al. Idiopathic pulmonary fibrosis: relationship between histopathologic features and mortality. Am J Respir Crit Care Med 2001; 164: $1025-1032$

107. Allen JT, Spiteri MA. Growth factors in idiopathic pulmonary fibrosis: relative roles. Respir Res 2002; 3: 13.

108. Chadelat K, Boule M, Corroyer S, et al. Expression of insulin-like growth factors and their binding proteins by bronchoalveolar cells from children with and without interstitial lung disease. Eur Respir J 1998; 11: 1329-1336.

109. King TE Jr. Interferon gamma-1b for the treatment of idiopathic pulmonary fibrosis. N Engl J Med 2000; 342: 974 975.

110. Raghu G, Johnson WC, Lockhart D, Mageto Y. Treatment of idiopathic pulmonary fibrosis with a new antifibrotic agent, pirfenidone: results of a prospective, open-label Phase II study. Am J Respir Crit Care Med 1999; 159: 1061-1069. 